\title{
Interaction of GAT1 with Ubiquitin-Specific Protease Usp14 in Synaptic Terminal
}

\author{
Dae-Hyun Seog ${ }^{1}$, Sang-Jin Kim², Young-Ju Joung', Sung Su Yea', Yeong-Hong Park', \\ Moo Seong $\mathrm{Kim}^{3}$, II Soo Moon ${ }^{4}$ and Won Hee Jang ${ }^{1}$ * \\ ${ }^{1}$ Departments of Biochemistry, ${ }^{2}$ Neurology, ${ }^{3}$ Neurosurgery, College of Medicine, Inje University, Busan 614735, Korea \\ ${ }^{4}$ Departments of Anatomy, College of Medicine, Dongguk University, Gyeongiu 780-714, Korea
}

Received April 27, 2010 /Accepted May 27, 2010

\begin{abstract}
$\gamma$-aminobutyric acid (GABA) is the major inhibitory neurotransmitter in the central nervous system. GABA transporters (GATs) control extracellular GABA levels by reuptake of released GABA from the synaptic cleft. However, how GATs are regulated has not yet been elucidated. Here, we used the yeast two-hybrid system to identify the specific binding protein(s) that interacts with the carboxyl (C)-terminal region of GAT1, the major isoform in the brain and find a specific interaction with the ubiquitin-specific protease 14 (Usp14), a deubiquitinating enzyme. Usp14 protein bound to the tail region of GAT1 and GAT2 but not to other GAT members in the yeast two-hybrid assay. The C-terminal region of Usp14 is essential for interaction with GAT1. In addition, these proteins showed specific interactions in the glutathione $S$-transferase (GST) pull-down assay. An antibody to GAT1 specifically co-immunoprecipitated Usp14 from mouse brain extracts. These results suggest that Usp14 may regulate the number of GAT1 at the cell surface.
\end{abstract}

Key words : $\gamma$-aminobutyric acid, $\gamma$-aminobutyric acid transporter, ubiquitin, protein-protein interaction, deubiquitinating enzyme

Introduction

Tightly regulated neurotransmitter release by the dynamics of synaptic vesicle and termination of synaptic neurotransmission is critical for normal brain function [6,13]. Plasma membrane neurotransmitter transporters are located in presynaptic terminal regions and glial cells [30]. These transporters remove neurotransmitter from the synaptic cleft. $\gamma$-aminobutyric acid (GABA) is the major inhibitory neurotransmitter in the brain $[13,24]$. The GABA system is a drug target for various psychiatric disorders and diseases such as epilepsy, anxiety disorders, schizophrenia and pain states which are related to the GABA system [11]. The plasma membrane $\gamma$-aminobutyric acid transporters (GATs) are predominantly localized at the presynaptic terminal of GABAergic neurons and play a major role in $\gamma$ -aminobutyric acid (GABA) uptake in the central nervous system [10,23]. There are four GATs, referred to as GAT1, GAT2, GAT3 and GAT4, which all belong to the $\mathrm{Na}^{+} / \mathrm{Cl}^{-}$ dependent neurotransmitter transporter family $[5,8,28,32,39]$. In the brain, GAT1 is most widely distributed isoform. Consistent with its function, GAT1 has been localized to the

\footnotetext{
*Corresponding author

Tel : +82-51-890-6974, Fax : +82-51-894-5801

E-mail : daehyun@inje.ac.kr (D. H. Seog) and whjang@inje.ac.kr (W. H. Jang)
}

axons of hippocampal neurons $[3,19,23,35]$. From this position, GAT1 can limit the diffusion of GABA and serve to terminate the inhibitory signaling by reimporting GABA into the axon terminus, where GABA can be recycled into synaptic vesicles [32,35]. In a study, GAT1 has been visualized in knock-in mice that express a GAT1-green fluorescent protein fusion (GAT1-GFP) [10]. The fluorescence is observed in axon terminals of neurons. At the ultrastructural level, GAT1 is found in inhibitory axon terminals [30], and this localization is well suited for the function associated with neurotransmitter uptake [19]. The topologies of GAT1 consist of intracellular amino $(\mathrm{N})$ and carboxyl (C) termini and 12 hydrophobic transmembrane domains that are presumed to be predominantly $a$-helical $[5,29]$.

Protein-protein interactions identify a link between the machinery involved in neurotransmitter release and uptake. Several studies have reported that GAT1 activity can be modulated by protein-protein interactions. Protein interaction between the N-terminal cytoplasmic tail of GAT1 and syntaxin $1 \mathrm{~A}$ causes a 4 -fold decrease in substrate transport rate $[4,16]$. The subcellular distribution of endogenous GAT1 in hippocampal neurons is under regulation by both protein kinase $C$ and tyrosine kinase $[4,26,34,37]$.

Identification of many proteins which interact with the C-terminus of neurotransmitter transporter has furthered understanding of transporter function and regulation. 
Interaction between glutamate transporter-associated protein (GTRAP) and the C-termini of glutamate transporter regulate cell surface expression of transporter [27]. Interaction between the C-terminus of the dopamine transporter (DAT) and PICK, a PKC-associated protein, regulates transport rate $[14,37,44]$. In an effort to further understand GAT1 mediated regulation, we used the yeast two-hybrid system to screen for proteins that interact with GAT1 and identified the ubiquitin-specific protease 14 (Usp14), a deubiquitinating enzyme [40]. The GAT1-Usp14 interaction suggests that GAT1 may be subject to dynamic regulation by Usp14 at the presynaptic terminal regions.

\section{Materials and Methods}

\section{Plasmid constructs}

A previously described mouse GAT1 cDNA [28,32] was utilized as a template to amplify the region coding for amino acids 557-599 using the appropriate primers. The amplified fragment was subcloned into pGEM T-easy vector (Promega Corp, Madison, WI, USA). The fragment was then EcoRl-restricted and subcloned into the EcoRI site of pLexA (Clontech, Palo Alto, CA, USA). The correct orientation and in-frame cloning of cDNA inserts was verified by restriction enzyme analysis and DNA sequencing. The coding region of Usp14 was amplified by RT-PCR from mouse brain and cloned into pGEM T-easy vector. After EcokI digestion, the Usp14 fragment was inserted into the EcoKI site of pB42AD (Clontech, Palo Alto, CA, USA).

Screening of GAT1-binding proteins by yeast
two-hybrid assay

The Matchmaker LexA two-hybrid system was used for screening according to the manufacturer's manual (Clontech). In brief, GAT1 cDNA fragment coding for amino acids 557-599 was fused to the DNA-BD region of the pLexA vector and the plasmid DNA was transformed into yeast strain EGY48 carrying the p8op-lacZ gene. The EGY48 yeast cells containing the GAT1 bait plasmid were transformed with the mouse brain cDNA library [42] and grown on synthetic dextrose (SD) plates supplemented with glucose but with no histidine, tryptophan, or uracil (SD/-His/-Trp/ -Ura). The selection of positive clones was performed on an $\mathrm{SD} /$-His/-Trp/-Ura/-Leu plate containing galactose, raffinose, X-gal, and BU salts. Library plasmids from positive colonies were isolated and rescued using Escherichia coli (E. coli) strain $\mathrm{KC} 8$ strain on ampicillin-resistant plates. Library inserts were analyzed by restriction digestion. Unique inserts were sequenced and DNA sequence analysis was performed with the BLAST algorithm at the National Center for Biotechnology Information (NCBI). Library plasmids were tested for interactions of the reporter gene in yeast by the retransformation.

\section{$\beta$-Galactosidase activity in liquid cultures of yeast}

The strength of the interactions between GAT1 and Usp14 constructs was assessed by measuring the $\beta$-galactosidase activity in liquid cultures or using the two-hybrid system. Yeast cells were co-transformed with the expression plasmids of the positive clones and the plasmids expressing GAT1 or other GATs. The $\beta$-galactosidase activity in liquid cultures of yeast was assayed as described previously [42]. In brief, mid-log phase transformed yeast cells were collected and permeabilized with $0.1 \%$ sodium dodecyl sulphate (SDS) and chloroform. An excess amount of chromogenic substrate o-nitrophenyl- $\beta$-D-galactoside was added to this lysate, and the mixture was incubated at $30^{\circ} \mathrm{C}$, and then the reaction was stopped by increasing $\mathrm{pH}$ to 11 by the addition of $1 \mathrm{M} \mathrm{Na}_{2} \mathrm{CO}_{3}$. The formation of the reaction product, o-nitrophenol, was determined by measuring absorbance at $420 \mathrm{~nm}$ on a spectrophotometer and normalizing for the reaction time and the cell density.

\section{Co-immunoprecipitation}

Mouse brain lysate was prepared as previously described [38]. Mouse brains were homogenized in ice-cold homogenization buffer (0.32 M sucrose, $4 \mathrm{mM}$ HEPES, $\mathrm{pH}$ 7.3) supplemented with protease inhibitors. The mouse brain homogenate supernatant was centrifuged again at $12,000 \times g$ for $15 \mathrm{~min}$, and the resulting supernatant was saved. For immunoprecipitation, the brain lysate was diluted in the same volume of $2 X$ binding buffer (50 mM HEPES, $240 \mathrm{mM} \mathrm{KCl}$, $2 \mathrm{mg} / \mathrm{ml} \mathrm{BSA}, 0.2 \%$ Triton X-100, pH 7.4) and incubated with anti-GAT1 antibody [35] or with control IgG overnight at $4^{\circ} \mathrm{C}$, followed by precipitation with protein-A Sepharose (Amersham Pharmacia, Piscataway, NJ, USA). The beads were collected by brief centrifugation and washed three times with TBS-T (20 mM Tris-HCl, pH 7.5, $0.15 \mathrm{M} \mathrm{NaCl}$, $0.1 \%$ Tween 20). The pellets were resuspended with Laemmli's loading buffer, the proteins were eluted and denatured by boiling for 2 minutes and then separated by SDS-PAGE. The gel was transferred to a nitrocellulose membrane and incubated with anti-Usp14 antibody (Abnova, Taipei, Taiwan). 


\section{Glutathione S-transferase (GST) pull-down assays}

Pull-down assays using GST fusion proteins were performed as follows. cDNAs encoding the C-terminal cytoplasmic region of GAT1, 2, 3 and 4 were cloned in pET 41, and the recombinant GST- GAT1, 2, 3 and 4 fusion proteins were expressed in bacterial strain BL21 GOLD (Stratagene, La Jolla CA, USA) after induction with $1 \mathrm{mM}$ isopropyl thio- $\beta$ -D-galactopyranoside (Fisher Biotech, South Australia, Australia). The fusion proteins were purified using glutathione-agarose beads (Sigma-Aldrich, St. Louis, MO, USA) according to the manufacturer's protocol. GST alone or GST fusion proteins were dialyzed for $2 \mathrm{hr}$ in PBS using Slide-A-Lyzer (Pierce, Rockford, IL, USA). Ten $\mu \mathrm{g}$ of each of the GST fusion proteins was then coupled to $50 \mu \mathrm{l}$ of glutathione-agarose beads by incubating at room temperature for $1 \mathrm{hr}$, followed by rinsing several times with PBS. The mouse brain lysate was incubated overnight at $4^{\circ} \mathrm{C}$ with the GST fusion protein-coupled glutathione beads. The beads were pelleted by centrifugation, washed three times with the extraction buffer (1\% Triton X-100 in PBS containing $10 \mu \mathrm{g} /$ $\mathrm{ml}$ each aprotinin, leupeptin, and pepstatin and $1 \mu \mathrm{M}$ phenylmethanesulfonyl fluoride), and once with PBS. The bound proteins were eluted from the glutathione beads with $100 \mu$ of Laemmli's loading buffer. The samples were boiled for $5 \mathrm{~min}$ and then processed for SDS-PAGE and immunoblot analysis with anti-Usp14 antibody.

\section{Results}

Identification of GAT1 interacting proteins by
yeast two-hybrid screening

The topology of GAT1 is composed of intracellular N-terminal and C-terminal regions and 12 transmembrane domains connected by interchanging extracellular and intra-

A
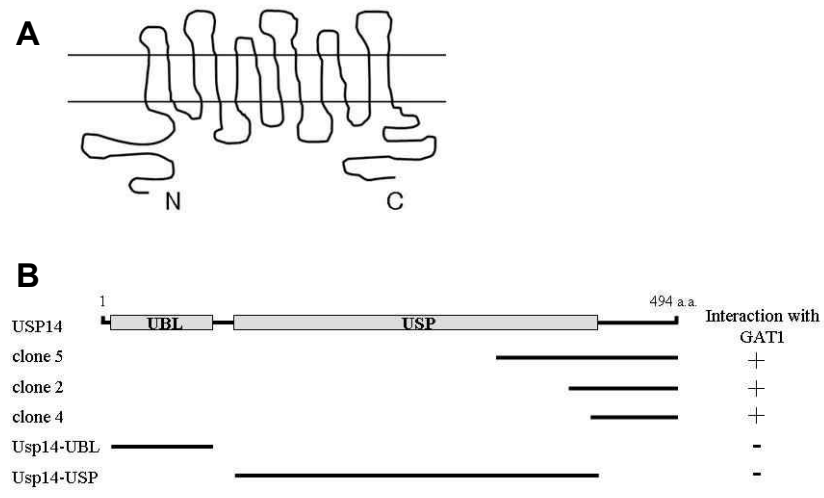

cellular loops (Fig. 1A) [5]. To examine GAT1-interacting proteins, we screened a mouse brain cDNA library through yeast two-hybrid assays using a portion of GAT1 C-terminal region as bait (Fig. 1A). From $5 \times 10^{6}$ colonies screened, we obtained eight positive clones. Three clones (clone 2, 4 and 5) of the positive clones were fragments of Usp14 containing the C-terminal region (Fig. 1B). Complementation experiments with the yeast two-hybrid system showed that C-terminal region of Usp14 supported growth of the yeast on nutrient-deficient media, indicating that the C-terminal region mediated this interaction (Fig. 1B).

Usp14 consists of an N-terminal ubiquitin-like (UBL) domain, followed by an ubiquitin-specific protease (USP) domain covering residues 102-408 [22]. To determine the minimal binding region of Usp14 required for the interaction with GAT1, we constructed deletion mutants of Usp14 and analyzed their interactions with GAT1 using the yeast two-hybrid assay. UBL domain and USP domain did not bind to GAT1. Only the C-terminus of Usp14 interacted with GAT1 in the yeast two-hybrid assay, as shown in Fig. 1B, demonstrating that the binding domain was located in the C-terminus region of Usp14 corresponding to amino acids 408-494.

In order to confirm whether Usp14 interacts with other GATs, we performed yeast two-hybrid assay. The C-terminal cytoplasmic tails of GAT2, GAT3 and GAT4 were tested for binding with Usp14. GAT2 also binds to Usp14, but there was no detectable binding between Usp14 and GAT3 or GAT4 (Fig. 2A). These data indicate that Usp14 specifically binds to the C-terminal cytoplasmic tails of GAT1 and GAT2.

GAT1 belongs to the $\mathrm{Na}^{+} / \mathrm{Cl}^{-}$dependent $S L C 6$ gene family, which also includes serotonin transporter (SERT) and dopamine transporter (DAT) [20,32]. When the cytoplasmic regions of SERT and DAT were tested for Usp14-binding

Fig. 1. Identification of the proteins interacting with GAT1 by yeast two-hybrid screening. (A) Putative topology of GAT1. The entire putative intracellular C-terminus of GAT1 fused to the binding domain of the $\mathrm{ADH} 1$ promoter was used to screen a mouse brain cDNA library. (B) Minimal GAT1 binding region in Usp14. Usp14 has ubiquitin-like (UBL) and ubiquitin-specific protease (USP) domains. UBL and USP domains are indicated in gray. a.a, the amino acid residue number. Clone 2, 4 and 5 were isolated from the yeast two-hybrid screen. Clone 2, 4 and 5 were overlapped at the C-terminal region of Usp14. Different truncations of Usp14 were constructed by PCR. Several truncated forms of Usp14 were tested in the yeast two-hybrid assay for interaction with GAT1. +, interaction with GAT1; -, no interaction with GAT1. 

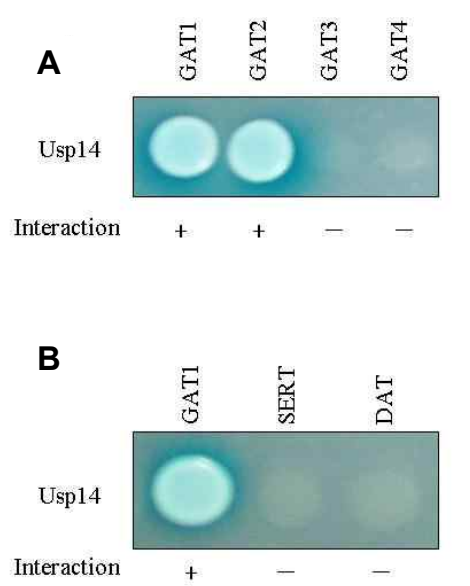

Fig. 2. Interaction between GATs and Usp14. (A) The C-terminal cytoplasmic regions of each GAT protein were fused to the pLexA DNA binding domain. Usp14 specifically interacted with GAT1 and GAT2 proteins but not with GAT3 or GAT4. (B) The C-terminal regions of SLC6 gene family were fused to the pLexA DNA binding domain. Usp14 specifically interacted with GAT1 but not with SERT or DAT. $(+$, interaction with Usp14; -, no interaction with Usp14). (C) The quantitation of $\beta$ - galactosidase activity in yeast cells resulting from the interaction of GAT1 with Usp14 and syntaxin 1A. by yeast two-hybrid assays, there was no detectable binding between Usp14 and the cytoplasmic regions of SERT and DAT (Fig. 2B). These data indicate that the interaction of Usp14 with SLC gene family is specific to the cytoplasmic region of GAT1 isoform.

As shown previously, syntaxin 1A physically interacts with GAT1 $[4,16]$. The strength of interaction of GAT1 with Usp14 and syntaxin 1A was examined quantitatively using $\beta$-galactosidase activity in a yeast two-hybrid reporter assay. This result indicates that Usp14 and syntaxin 1A had same level affinity for GAT1 (Fig. 2C). Therefore, the interaction of GAT1 with Usp14 appeared to be sufficient in vivo.

\section{GAT1 is associated with Usp14 in vitro and in vivo}

To confirm the interaction between the cytoplasmic tail of GAT1 and Usp14 in a different experimental setting, we incubated GAT1, GAT2, GAT3, GAT4 or SERT cytoplasmic tails, which were expressed in E. coli with GST tag and immobilized on beads, with whole brain lysates from mice. Immunoblot analysis showed that Usp14 interacted with GAT1 and GAT2, but not with GAT3, GAT4 and SERT, consistent with the yeast two-hybrid results (Fig. 3A). This result further indicates that the GAT1 and GAT2 directly interact with Usp14.

In order to determine whether the interaction between GAT1 and Usp14 occurs in vivo, we performed co-immunoprecipitation experiments using mouse brain lysates. Lysates from mouse brain were incubated with a GAT1 or SERT antibody. Protein G-agarose beads selectively precipitated the immuno-complexes, which were subsequently separated by SDS-PAGE and immunoblotted with Usp14 antibody. As shown in Fig. 3B, Usp14 was co-immunoprecipitated with GAT1 but not with SERT, which is
A
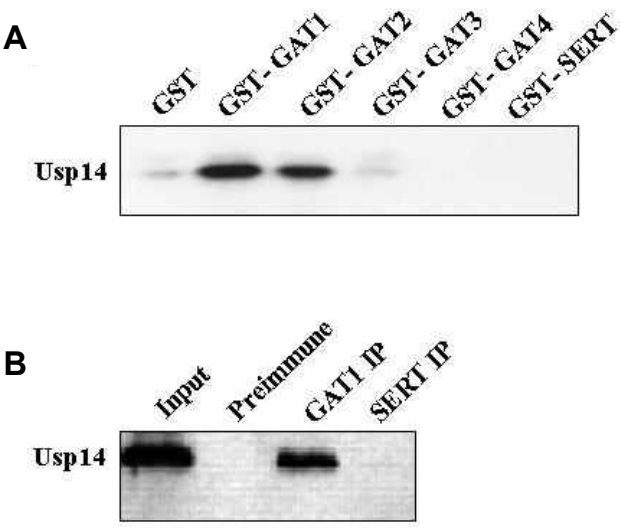

Fig. 3. Association of GAT1 and Usp14 in the GST pull-down assay and co-immunoprecipitation. (A) Proteins in the mouse brain lysate were allowed to bind to GST alone, GST-GAT1，GST-GAT2，GST-GAT3， GST-GAT4 or GST-SERT fusion proteins. The elution fractions were resolved by SDS-PAGE and immunoblot analysis was performed using an antibody to Usp14. (B) Mouse brain lysate was immunoprecipitated with anti-Usp14 antibody, anti-SERT antibody or preimmune serum and then the precipitates were immunoblotted with anti-Usp14 antibody. Input: 5\% of the mouse brain lysates used for each co-immunoprecipitation assay.

consistent with the yeast two-hybrid and GST pull-down results. This result indicates that Usp14 is a specific binding partner of GAT1 in vivo.

\section{Discussion}

The redistribution of neurotransmitter transporters and receptors is subject to regulation [6,13]. Redistribution modulator proteins including protein kinase $C$ and syntaxin $1 \mathrm{~A}$ have been identified. Syntaxin $1 \mathrm{~A}$ interacts with the $\mathrm{N}$-terminal cytoplasmic region of GAT1 and increases its presynaptic 
terminal expression $[14,16]$. However, the modulator proteins of the GAT1 C-terminal cytoplasmic tail have not yet been reported.

In this study we demonstrate for the first time that the GAT1 directly interacts with Usp14. First, we showed that Usp14 directly interacts with GAT1 in the yeast two-hybrid system (Fig. 1B). Secondly, we demonstrated the interaction of Usp14 with the C-terminal cytoplasmic region of GAT1 in GST pull-down assay and co-immunoprecipitation study (Fig. 3). Furthermore our result also demonstrated that the C-terminal domain of Usp14 is required for the interaction with GAT1 (Fig. 1B).

Protein ubiquitin was discovered as a mark for intracellular proteolysis [1,12,40]. Membrane transporters are subject to ubiquitination. Ubiquitination plays a prominent role in supporting endocytosis of cell membrane transporter $[17,31,33,43]$. Previous study shows that the ubiquitination of neurotransmitter transporters can target the transporters to proteasomal degradation or redirect them on endocytotic pathway to the lysosome $[9,21,36,41,46]$. Protein deubiquitination has been identified as an important regulatory step in the ubiquitin-dependent pathways [40]. Deubiquitination is carried out by the deubiquitinating enzymes (DUBs) $[12,40]$. DUBs remove ubiquitins from protein substrates and are essential for regulating protein stability and localization [40]. Usp14 is one of the DUBs [7]. Usp14 contains an UBL domain at the N-terminus [22]; the UBL domain interacts with $26 \mathrm{~S}$ proteasome. This interaction results in the enhancement of the deubiquitinating activity of Usp14. Homozygous mutation of mouse USP14 gene develops severe ataxia, which may result from a $30 \%$ loss of monomeric ubiquitin in brain $[15,18,45]$. The spontaneous ataxia $\left(a x^{J}\right)$ mutant mice, encoding Usp14, display both increased GABA neurotransmitter levels at Purkinje cells surface membranes accompanied by enlarged inhibitory postsynaptic current (IPSC) [25]. The rescue of the ataxia mice by neuronal-specific expression of Usp14 suggest that Usp14 localizes at the presynapse and alters synaptic activity [45]. Interestingly, mice deficient for the GAT1 develop severe ataxia due to disturbed GABA re-uptake from synaptic cleft [11]. It is therefore a possible scenario that the ataxia is closely linked to the level of Usp14 dependent GAT1 turnover within cerebellular circuits.

How does Usp14 regulate the activity of GAT1? One potential regulatory mechanism is the increased level of GAT1 in synaptic terminal membrane. Membrane embedded re- ceptors and transporters are subject to ubiquitination $[9,17,21,36]$. Ubiquitin-mediated mechanism seems to be particularly for endocytosis of receptors and membrane transporter; many studies focus on the EGF receptor (EGFR), a tyrosine kinas receptor [2]. In the absence of the EGF ligand, the EGFR is located at caveolae and noncaveole rafts. Usp14 has evolved a specialized function in membrane transporter to regulate the ubiquitin side chain length of proteins [12]. Because proteins with short ubiquitin chains are thought to be poor substrates for the proteasome, Usp14 may be disturbed endocytosis pathway, leading to maintenance of the transporters at the cell surface. Deubiquitination of GAT1 by Usp14 would thus be expected to reduce the rate of GAT1 degradation and result in an increased steady state level of GAT1. Although an exact molecular mechanism remains to be elucidated, Usp14 may be a novel candidate to participate in regulation of GAT1 turnover at the synaptic terminal membrane.

\section{Acknowledgement}

This work was supported by an Inje University Research Grant for 2009.

\section{References}

1. Alves-Rodrigues, A., L. Gregori, and M. E. Figueiredo-Pereira. 1998. Ubiquitin, cellular inclusions, and their role in neurodegeneration. Trends Neurosci. 21, 516-520.

2. Alwan, H. A., E. J. van Zoelen, and J. E. van Leeuwen. 2003. Ligand-induced lysosomal epidermal growth factor receptor (EGFR) degradation is preceded by proteasome-dependent EGFR de-ubiquitination. J. Biol. Chem 278, 35781-35790.

3. Augood, S., A. Herbison, and P. Emson. 1995. Localization of GAT-1 GABA transporter mRNA in rat striatum: cellular coexpression with GAD67 mRNA, GAD67 immunoreactivity, and parvalbumin mRNA. J. Neurosci. 15, 865-874.

4. Beckman, M., E. Bernstein, and M. Quick. 1998. Protein kinase $C$ regulates the interaction between a GABA transporter and syntaxin 1A. J. Neurosci. 18, 6103-6112.

5. Bennett, E. R., H. Su, and B. I. Kanner. 2000. Mutation of arginine 44 of GAT-1, a $\left(\mathrm{Na}^{+}+\mathrm{Cl}\right)$-coupled $\gamma$-aminobutyric acid transporter from rat brain, impairs net flux but not exchange. J. Biol. Chem 275, 34106-34113.

6. Blakely, R. D. and A. L. Bauman. 2000. Biogenic amine transporters: regulation in flux. Curr. Opin. Neurobiol. 10, 328-336.

7. Borodovsky, A., B. M. Kessler, R. Casagrande, H. S. Overkleeft, K. D. Wilkinson, and H. L. Ploegh. 2001. A novel active site-directed probe specific for deubiquitylating en- 
zymes reveals proteasome association of USP14. EMBO J. 20, 5187-5196.

8. Brown, A., D. Grimm, T. Muth, L. Dunbar, S. Maday, X. Lou, M. Farquar, and M. Caplan. 2001. GIPC associates with GAT2 and may regulate its targeting by a novel mechanism. Mol. Biol. Cell 12, 345a.

9. Buttner, C., S. Sadtler, A. Leyendecker, B. Laube, N. Griffon, H. Betz, and G. Schmalzing. 2001. Ubiquitination precedes internalization and proteolytic cleavage of plasma membrane-bound glycine receptors. J. Biol. Chem 276, 4297842985.

10. Chiu, C., K. Jensen, I. Sokolova, D. Wang, M. Li, P. Deshpande, N. Davidson, I. Mody, M. Quick, S. Quake, and H. Lester. 2002. Number, density, and surface/cytoplasmic distribution of GABA transporters at presynaptic structures of knock-in mice carrying GABA transporter subtype 1-green fluorescent protein fusions. J. Neurosci. 22, 1025110266.

11. Chiu, C. S., S. Brickley, K. Jensen, A. Southwell, S. McKinney, S. Cull-Candy, I. Mody, and H. A. Laster. 2005. GABA transporter deficiency causes tremor, ataxia, nervousness, and increased GABA-induced tonic conductance in cerebellum. J. Neurosci. 25, 3234-3245.

12. Chung, C. H. and S. H. Baek. 1999. Deubiquitinating enzymes: their diversity and emerging roles. Biochem Biophys. Res. Commun. 266, 633-640.

13. Clark, J. and S. Amara. 1993. Amino acid neurotransmitter transporters: structure, function, and molecular diversity. BioEssays. 15, 323-332.

14. Corey, J., N. Davidson, H. Lester, N. Brecha, and M. Quick. 1994. Protein kinase C modulates the activity of a cloned gamma-aminobutyric acid transporter expressed in Xenopus oocytes via regulated subcellular redistribution of the transporter. J. Biol. Chem 269, 14759-14767.

15. Crimmins, S., Y. Jin, C. Wheeler, A. K. Huffman, C. Chapman, L. E. Dobrunz, A. Levey, K. A. Roth, J. A. Wilson, and S. M. Wilson. 2006. Transgenic rescue of ataxia mice with neuronal-specific expression of ubiquitin-specific protease 14. J. Neurosci. 26, 11423-11431.

16. Deken, S., M. Beckman, L. Boos, and M. Quick. 2000. Transport rates of GABA transporters: regulation by the $\mathrm{N}$-terminal domain and syntaxin 1A. Nat. Neurosci. 3, 998-1003.

17. DiAntonio, A., A. P. Haghighi, S. L. Portman, J. D. Lee, A. M. Amaranto, and C. S. Goodman. 2001. Ubiquitination-dependent mechanisms regulate synaptic growth and function. Nature 412, 449-452.

18. Ehlers, M. D. 2003. Ubiquitin and synaptic dysfunction: ataxic mice highlight new common themes in neurological disease. Trends Neurosci. 26, 4-7.

19. Engel, D., D. Schmitz, T. Gloveli, C. Frahm, U. Heinemann, and A. Draguhn. 1998. Laminar difference in GABA uptake and GAT-1 expression in rat CA1. J. Physiol. 512, 643-649.

20. Haase, J., A. M. Killian, F. Magnani, and C. Williams. 2001. Regulation of the serotonin transporter by interacting proteins. Biochem Soc. Trans. 29, 722-728.
21. Hicke, L. and H. Riezman. 1996. Ubiquitination of a yeast plasma membrane receptor signals its ligand-stimulated endocytosis. Cell 84, 277-287.

22. Hu, M., P. Li, L. Song, P. D. Jeffrey, T. A. Chenova, K. D. Wilkinson, R. E. Cohen, and Y. Shi. 2005. Structure and mechanisms of the proteasome-associated deubiquitinating enzyme USP14. EMBO J. 24, 3747-3756.

23. Isaacson, J., J. Solis, and R. Nicoll. 1993. Local and diffuse synaptic actions of GABA in the hippocampus. Neuron 10, 165-175.

24. Kwong, W., W. Chan, K. Lee, M. Fan, and D. Yew. 2000. Neurotransmitters, neuropeptides and calcium binding proteins in developing human cerebellum: a review. Histochem J. 32, 521-534.

25. Lappe-Siefke, C., S. Loebrich, W. Hevers, O. B. Waidmann, M. Schweizer, S. Fehr, J. M. Fritschy, I. Dikic, J. Eilers, S. M. Wilson, and M. Kneussel. 2009. The ataxia (axJ) mutation causes abnormal GABAA receptor turnover in mice. PLOS Genet. 9, e1000631.

26. Law, R., A. Stafford, and M. Quick. 2000. Functional regulation of gamma-aminobutyric acid transporters by direct tyrosine phosphorylation. J. Biol. Chem 275, 23986-23991.

27. Lin, C. I., I. Orlov, A. M. Ruggiero, M. Dykes-Hoberg, A. Lee, M. Jackson, and J. D. Rothstein. 2001. Modulation of the neuronal glutamate transporter EAAC1 by the interacting protein GTRAP3-18. Nature 410, 84-88.

28. Liu, Q. R., S. Mandiyan, H. Nelson, and N. Nelson. 1992. A family of genes encoding neurotransmitter transporters. Proc. Natl. Acad Sci. USA 89, 6639-6643.

29. Mager, S., N. Kleinberger-Doron, G. I. Keshet, N. Davidson, B. I. Kanner, and H. A. Lester. 1996. Ion binding and permeation at the GABA transporter GAT1. J. Neurosci. 16, 5405-5414.

30. Minelli, A., N. Brecha, C. Karschin, S. DeBias, and F. Conti. 1996. GAT-1, a high-affinity GABA plasma membrane transporter, is localized to neurons and astroglia in the cerebral cortex. J. Neurosci. 15, 7734-7746.

31. Mukherjee, S., R. N. Ghosh, and F. R. Maxfield. 1997. Endocytosis. Physiol. Rev. 77, 759-803.

32. Nelson, N. 1998. The family of $\mathrm{Na}+\mathrm{Cl}-$ neurotransmitter transporters. J. Neurochem 71, 1785-1803.

33. Park, M., E. C. Penick, J. G. Edwards, J. A. Kauer, and M. D. Ehlers. 2004. Recycling endosomes supply AMPA receptors for LTP. Science 305, 1972-1975.

34. Quick, M., J. Corey, N. Davidson, and H. Lester. 1997. Second messengers, trafficking-related proteins, and amino acid residues that contribute to the functional regulation of the rat brain GABA transporter GAT1. J. Neurosci. 17, 2967-2979.

35. Radian, R., O. Ottersen, J. Storm-Mathisen, M. Castel, and B. Kanner. 1990. Immunocytochemical localization of the GABA transporter in rat brain. J. Neurosci. 10, 1319-1330.

36. Saliba, R. S., G. Michels, T. C. Jacob, M. N. Pangalos, and S. J. Moss. 2007. Activity-dependent ubiquitination of GABA(A) receptors regulates their accumulation at synaptic sites. J. Neurosci. 27, 13341-13351. 
37. Sato, K., H. Betz, and P. Schloss. 1995. The recombinant GABA transporter GAT1 is downregulated upon activation of protein kinase C. FEBS Lett. 375, 99-102.

38. Setou, M., T. Nakagawa, D. H. Seog, and N. Hirokawa. 2000. Kinesin superfamily motor protein KIF17 and mLin-10 in NMDA receptor-containing vesicle transport. Science 288, 1796-1802

39. Sloan, J. and S. Mager. 1999. Cloning and functional expression of a human $\mathrm{Na}(+)$ and $\mathrm{Cl}(-)$-dependent neutral and cationic amino acid transporter $\mathrm{B}(0+)$. J. Biol. Chem 274, 23740-23745.

40. Soboleva, T. A. and R. T. Baker. 2004. Deubiquitinating enzymes: their functions and substrate specificity. Curr. Protein Pept. Sci. 5, 191-200.

41. Speese, S. D., N. Trotta, C. K. Rodesch, B. Aravamudan, and K. Broadie. 2003. The ubiquitin proteasome system acutely regulates presynaptic protein turnover and synaptic efficacy. Curr. Biol. 13, 899-910.

42. Takeda, S., H. Yamazaki, D. H. Seog, Y. Kanai, S. Terada, and N. Hirokawa. 2000. Kinesin superfamily protein 3 (KIF3) motor transports fodrin-associating vesicles important for neurite building. J. Cell Biol. 148, 1255-1265.

43. Terrell, J., S. Shih, R. Dunn, and L. Hicke. 1998. A function for monoubiquitination in the internalization of a $G$ protein-coupled receptor. Mol. Cell 1, 193-202.

44. Torres, G. E., W. D. Yao, A. R. Mohn, H. Quan, K. M. Kim, A. I. Levey, J. Staudinger, and M. G. Caron. 2001. Functional interaction between monoamine plasma membrane transporters and synaptic PDZ domain-containing protein PICK1. Neuron 30, 121-134.

45. Wilson, S. M., B. Bhattacharyya, R. A. Rachel, V. Coppola, L. Tessarollo, D. B. Householder, C. F. Fletcher, R. J. Miller, N. G. Copeland, and N. A. Jenkins. 2002. Synaptic defects in ataxia mice result from a mutation in Usp14, encoding a ubiquitin-specific protease. Nat. Genet. 32, 420-425.

46. Yi, J. J. and M. D. Ehlers. 2005. Ubiquitin and protein turnover in synapse function. Neuron 47, 629-632.

초록 : GAT1과 ubiquitin-specific protease Usp14의 결합

석대현 ${ }^{1} \star$ 김상진 ${ }^{2} \cdot$ 정영주 ${ }^{1} \cdot$ 예성수 ${ }^{1} \cdot$ 박영홍 $^{1} \cdot$ 김무성 ${ }^{3} \cdot$ 문일수 $^{4} \cdot$ 장원희 ${ }^{1} \star$

(인제대학교 의과대학 ${ }^{1}$ 생화학교실, ${ }^{2}$ 신경과학교실, ${ }^{3}$ 신경외과학교실, ${ }^{4}$ 동국대학교 의과대학 해부학교실)

$\gamma$-aminobutyric acid (GABA)는 중추신경계에서 억제성으로 작용하는 주요한 신경전달물질이다. GABA 수송 체(GAT)는 연접간격에 존재하는 GABA를 세포 내로 재 흡수하여 GABA의 농도를 조절한다. 그런데 GABA 수송 체가 어떻게 조절되는지는 아직 밝혀지지 않았다. 본 연구에서는 효모 two-hybrid system을 사용하여 뇌의 주요 GABA 수송체인 GAT1의 C-말단과 특이적으로 결합하는 ubiquitin-specific protease 14 (Usp14)를 분리하였다. Usp14는 GABA 수송체 GAT1및 GAT2와는 결합하지만, 다른 GAT isoform과는 결합하지 않았다. GAT1과의 결 합에는 Usp14의 C-말단부위가 필수적으로 관여함을 확인하였다. 또한 이 단백질간의 결합을 GST pull-down assay로 확인하였으며, 생쥐 뇌 균질액의 co-immunoprecipitation을 통하여 in vivo에서도 GAT1과 Usp14가 결합함 을 확인하였다. 이러한 결과들은 Usp14가 GAT1과 결합하여 세포막에 존재하는 GAT1의 수를 조절하는 역할을 할 가능성을 시사한다. 